\title{
El impacto de las vacunas en países con bajos ingresos y países con altos ingresos
}

\author{
Leif Gothefors \\ Departamento de Ciencias Clínicas/Pediatría, Universidad de Umeå, Umeå, Suecia
}

\section{Palabras clave}

Vacunas · Inmunización, programa ampliado

\section{Extracto}

La vacunación ha llegado a ser la medida sanitaria más efectiva para el control de las enfermedades infecciosas después de la disponibilidad de agua potable limpia. La historia de la vacunación está marcada por grandes esperanzas y algunas decepciones. En particular, la segunda mitad del siglo XX ha sido testigo del desarrollo de notables proyectos de vacunación. Aunque existe la posibilidad de que la poliomielitis y el sarampión puedan ser erradicados en el curso de unos pocos años, casi tres millones de personas, habitualmente niños menores de 5 años, fallecen cada año por enfermedades que son evitables por medio de vacunas. Los países en vías de desarrollo se están esforzando para obtener las vacunas para niños que las necesitan desesperadamente. No obstante, en Europa y Norteamérica, la población llega a ser descuidada con respecto a las vacunas: 'Estas enfermedades ya no constituyen una amenaza y la vacuna es más peligrosa que la enfermedad'. Estos conceptos erróneos han causado brotes de sarampión, difteria y tos ferina. La comunidad internacional debe seguir dedicando los recursos, fondos y potencial humano necesarios para aprovechar plenamente la promesa de que las vacunas sustentan el alivio de la miseria humana.

Copyright $\odot 2008$ Nestec Ltd., Vevey/S. Karger AG, Basel

En 2007, la revista British Medical Journal solicitó a sus lectores que nombraran los avances médicos más importantes desde 1840 [1]. El resultado de esta encuesta, no demasiado científica, consistió en un conjunto de cuatro elementos prin- cipales: saneamiento (agua limpia y eliminación de aguas servidas), antibióticos, anestesia y vacunas. Si se trataba de basar el voto de cada cual en el número de vidas salvadas, las vacunas parecían imbatibles (tabla 1).

La erradicación exitosa de la viruela en 1977 llevó al optimismo comprensible de que las enfermedades infantiles también podrían ser erradicadas por medio de la vacunación. En 1974, la OMS diseñó el Programa Ampliado de Inmunización (EPI) para proporcionar vacunas básicas a los niños de todo el mundo. A la sazón, se inmunizó a menos del 5\% de los niños contra las 6 enfermedades seleccionadas (tuberculosis, difteria, tétanos, tos ferina, poliomielitis y sarampión) y los programas de inmunización se limitaron en gran medida a países industrializados y, aun así, se pusieron en práctica sólo parcialmente. A pesar de las intenciones de la OMS (a través del trabajo del EPI) y la buena disponibilidad de vacunas económicas, seguras y efectivas, a escala global no se ha erradicado todavía ningún otro agente patógeno. No obstante, la erradicación de la poliomielitis y el sarampión parece constituir una posibilidad y, por lo tanto, la parte principal de este artículo se dedicará a dichos esfuerzos. Sólo se abordan vacunas utilizadas en el EPI (actualmente o en un futuro próximo).

\section{Algunas definiciones}

Erradicación es una reducción permanente a cero en todo el mundo de una infección causada por un agente específico; en consecuencia, las medidas de intervención pueden suspenderse.

Eliminación es la reducción a cero de la incidencia de una enfermedad específica en una zona geográfica definida; las medidas de intervención tienen que continuar dado que existe

\section{KARGER}

Fax +4161306 1234 E-Mail karger@karger.ch www.karger.com
(C) 2008 Nestec Ltd., Vevey/S. Karger AG, Basel 0252-8185/08/0662-0055\$24.50/0

Accesible online en:

www.karger.com/ans
Leif Gothefors, Prof. em.

Department of Clinical Sciences/Paediatrics

Umeå University

SE-901 85 Umeå (Sweden)

Tel. +4690785 2102, Fax +469012 37 28, E-Mail leif.gothefors@pediatri.umu.se 
Tabla 1. Mortalidades por enfermedades contra las cuales la vacunación es corriente; Australia 1926-2000

\begin{tabular}{lrrrrrr}
\hline Periodo & Difteria & Tosferina & Tétanos & Poliomielitis & Sarampión & $\begin{array}{l}\text { Población estimada } \\
\text { millones }\end{array}$ \\
\hline $1926-1935$ & 4.073 & 2.808 & 879 & 430 & 1.102 & 6,6 \\
$1936-1945$ & 2.791 & 1.693 & 655 & 618 & 822 & 7,2 \\
$1946-1955$ & 624 & 429 & 625 & 1.013 & 495 & 8,6 \\
$1956-1965$ & 44 & 58 & 280 & 123 & 210 & 11 \\
$1966-1975$ & 11 & 22 & 82 & 2 & 146 & 13,7 \\
$1976-1985$ & 2 & 14 & 31 & 2 & 62 & 14,9 \\
$1986-1995$ & 2 & 9 & 21 & 0 & 32 & 17,3 \\
$1996-2000$ & 0 & 9 & 5 & 0 & 0 & 18,7 \\
\hline
\end{tabular}

Las cursivas indican la década cuando se inició la vacunación para la enfermedad.

Reproducido con autorización del NSW Public Health Bulletin [2].

la posibilidad de la reinstauración de la enfermedad a partir de otras zonas.

Una enfermedad puede tenerse bajo control, es decir, reducir la incidencia, la morbilidad o la mortalidad hasta un nivel localmente aceptado; no obstante, las medidas de intervención prosiguen y se necesitan para mantener dicha reducción.

\section{Viruela}

Durante el siglo XIX, la mayoría de los países industrializados introdujeron la vacunación y, en 1900, un cierto número de países de Europa septentrional se habían liberado de la viruela. No obstante, la vacunación se mantuvo hasta la década de los 70, como medida protectora en caso de la reaparición de la viruela.

En 1959, la OMS decidió emprender un programa de erradicación global. Aunque se instauraron campañas de vacunación masiva, el progreso fue desalentador, especialmente en África y en el subcontinente indio. Las limitaciones de los recursos financieros y el potencial humano disponible (a la sazón, el personal de la OMS se dedicaba a la erradicación del paludismo) pudieron haber contribuido al fracaso relativo. En 1966, la estrategia se cambió a 'vigilancia y contención', también denominada 'vacunación cíclica', que incluye la constitución de una barrera de personas inmunes en torno al caso y a sus contactos [3]. Se demostró que de este modo se obtenía un enfoque más satisfactorio, hasta el punto que el último caso espontáneo de viruela se diagnosticó en Somalia en 1977; subsiguientemente, en 1979, la OMS declaró la viruela oficialmente erradicada en la población mundial. En esta situación, ¿no habría sido prudente destruir las conocidas existencias de laboratorio restantes del virus de la viruela, por ejemplo, las almacenadas en el Centro para el Control de Enfermedades y en el Instituto Vector de Novosibirsk? Varias organizaciones cien- tíficas recomendaron la destrucción del virus [4], pero el problema durante la última década adquirió una connotación política. En la Asamblea de la Salud Mundial de 2007 se recomendó (por fin) la destrucción de las existencias del virus pero no hasta que el '... resultado de la investigación crucial con respecto a una respuesta sanitaria mejorada a un brote así lo permitiera' [5].

En los años que siguieron al 11 de septiembre, la amenaza de un ataque bioterrorista basado en la viruela como arma alentó a que en 2002 las autoridades de EE.UU. reinstauraran transitoriamente la vacunación antivariólica para el personal militar y el personal civil de alto riesgo. En estudios de efectos adversos probablemente relacionados con la vacuna se registraron 21 casos de carditis con 3 fallecimientos en uno de los estudios (37.901 civiles) y 39 casos de efectos adversos neurológicos graves en otro estudio (665.000 personas entre el personal militar y la población civil) [6,7]. No obstante, la prevalencia de estas enfermedades en la población en estudio fue similar a la prevalencia prevista en la población en general. Sin embargo, al respecto, la política de la OMS se había opuesto a una vacunación preventiva de la viruela, y el Instituto de Medicina criticó este programa del Centro para el Control de Enfermedades, '... la consecuencia de una decisión política extraordinaria de vacunar a personas contra una enfermedad que no existe con una vacuna que plantea algunos riesgos muy conocidos' [8].

\section{Tuberculosis}

El informe anual 'Control global de la tuberculosis en 2007' [9] concluye que 'la tasa de incidencia global de la TB llegó a su máximo en algún momento entre 2000 y 2005 ... y la epidemia de TB global se encuentra actualmente en el umbral de la declinación'. Hoy día, el mecanismo principal para el logro de 
este objetivo se basa en el éxito obtenido con el Tratamiento Observado Directamente, a Corto Plazo (DOTS, por sus siglas en ingles), que se introdujo en 1995. La vacuna con el Bacilo Calmette-Guérin (BCG) no se menciona en el informe y cabe preguntarse si se trata de una vacuna ya obsoleta.

Se estima que alrededor de $1 / 3$ de la población global está infectada asintomáticamente de tuberculosis (TB) y aproximadamente del 5 al 10\% presentará la enfermedad clínica [10]. De todas las muertes evitables, la TB es directamente responsable de más de la cuarta parte. La mayoría de los nuevos casos y los fallecimientos corresponde a países en vías de desarrollo en los cuales los niños frecuentemente están infectados.

Los países industrializados pudieron registrar una declinación de la incidencia durante varios años, pero este desarrollo positivo cambió hacia el final del siglo XX. Esto se debió a la inmigración de países endémicos, individuos VIH positivos, usuarios de drogas y prisioneros [10].

La vacuna BCG se utilizó por primera vez en 1921, por vía oral en lactantes [11], y es una de las vacunas más utilizadas a pesar de los datos contradictorios sobre su eficacia protectora. Posee un efecto confirmado (50 a $80 \%$ ) frente a la meningitis y la TB diseminada en niños, pero no evita la infección primaria o, lo que es más importante, la reactivación de la infección pulmonar latente, que es la fuente principal de propagación de la bacteria en la comunidad. Este fallo, conjuntamente con la creciente pandemia de VIH/SIDA y la aparición de micobacterias resistentes a múltiples fármacos, amenaza con arrollar las estrategias actuales de control de la TB.

En los países con carga elevada de enfermedad tuberculosa debe administrarse una dosis de vacuna BCG a todos los lactantes tan pronto sea posible después del nacimiento. La excepción corresponde a los niños conocidos por estar infectados por el VIH [12]. Cuando la carga de TB es baja, la BCG se administra únicamente a grupos de riesgo de la enfermedad o es sustituida completamente por la detección y el tratamiento precoz de los casos. La OMS no recomienda la vacunación de los adultos ni la vacunación repetida [10]. Así, la vacuna BCG sigue siendo todavía uno de los tres factores sobre los cuales se basa el control de la TB: diagnóstico precoz y tratamiento adecuado, rastreo de los contactos y vacunación con BCG. Es perentoria la necesidad de contar con una vacuna más efectiva que pudiese evitar la reactivación de la bacteria.

\section{Difteria}

La difteria ha sido una de las enfermedades infantiles más temibles, caracterizada por brotes devastadores. Afortunadamente, la mayoría de las infecciones por Corynebacterium diphtheriae presentan un curso clínico leve o son totalmente asintomáticas; sin embargo, las tasas de mortalidad alcanzaron el 50\% durante una gran epidemia en Europa y en EE.UU. en la década de 1880. La tasa de mortalidad declinó hasta alrededor del 15\% durante la primera guerra mundial (debido principalmente al empleo de antitoxina) y puede alcanzar todavía, a pesar del tratamiento moderno, un $10 \%$ en regiones endémicas $[13,14]$. Se ha estimado que antes de que la vacuna llegue a estar fácilmente disponible aparecerá cada año en países en vías de desarrollo alrededor de un millón de casos de difteria con la mortalidad subsiguiente de 50.000 a 60.000 personas [13]. La vacuna llegó a formar parte del EPI en 1974 y, con gran probabilidad como consecuencia de ello, el número global de casos de difteria comunicados se redujo en más de un $90 \%$ (fig. 1) durante el periodo comprendido entre $1980 \mathrm{y}$ 2000.

Hay países, particularmente en el África subsahariana, pero también en regiones de América del Sur y Asia oriental, donde la cobertura de inmunización con tres dosis de vacuna de difteria (administrada en forma de difteria/tétanos/tos ferina, células enteras, DTTe) es $<50 \%$ de la cohorte de nacimiento [13]. En tales países, donde la difteria es todavía endémica, la morbilidad y la mortalidad debidas a esta enfermedad siguen siendo elevadas, y los niños en edad preescolar y escolar son corrientemente los más afectados.

En la mayoría de los países industrializados, con una cobertura vacunal elevada, aunque la difteria endémica ha desaparecido o es extremadamente rara, todavía aparecen brotes. Estudios serológicos realizados en la década de 1980 indicaban que incluso en Europa y en EE.UU., con una elevada cobertura vacunal, una gran proporción, a menudo de hasta el $50 \%$ de adultos, era propensa a presentar difteria [15]. Se describen dos motivos importantes: (1) La inmunidad inducida por la vacuna se disipa en el transcurso del tiempo, a menos que se administren inmunizaciones de refuerzo durante el periodo; (2) la circulación 'normal' de toxígeno $C$. diphtheriae se reduce por el uso generalizado de la vacuna contra la difteria y, en consecuencia, se reduce el efecto de refuerzo natural sobre el sistema inmunitario [15].

Si en una situación con cobertura vacunal baja en niños y una considerable brecha inmunitaria en adultos se introdujera un nuevo biotipo de $C$. diphtheriae, cabría la posibilidad de una epidemia. El hacinamiento y una higiene personal deficiente constituyen también factores importantes. Esto es probablemente lo que sucedió en la federación rusa, donde en la década de 1990 reapareció la difteria con la consecuencia de una epidemia. Esta, que se diseminó en todos los estados recién independizados y en los estados bálticos, causó más de 157.000 casos y 5.000 fallecimientos. Casi la mitad de las muertes correspondieron a personas adultas $[14,15]$. Por lo menos hasta 1986, la mayoría de estos países tenían una cobertura de inmunización infantil razonablemente elevada, incluyendo una dosis de refuerzo en torno a los 15 años de edad. No obstante, la inmunogenicidad de la vacuna utilizada fue puesta en entredicho. La diseminación de la epidemia en los estados recién independizados fue facilitada por desplazamientos demográficos a gran escala. Esto podría suceder de nuevo a causa de los siempre crecientes viajes internacionales, que propician la introducción de cepas toxígenas en países sometidos a inestabi- 
Fig. 1. Incidencia anual global de difteria reportada y cobertura de la DTT3, 19802006. Reproducido con autorización de la OMS.

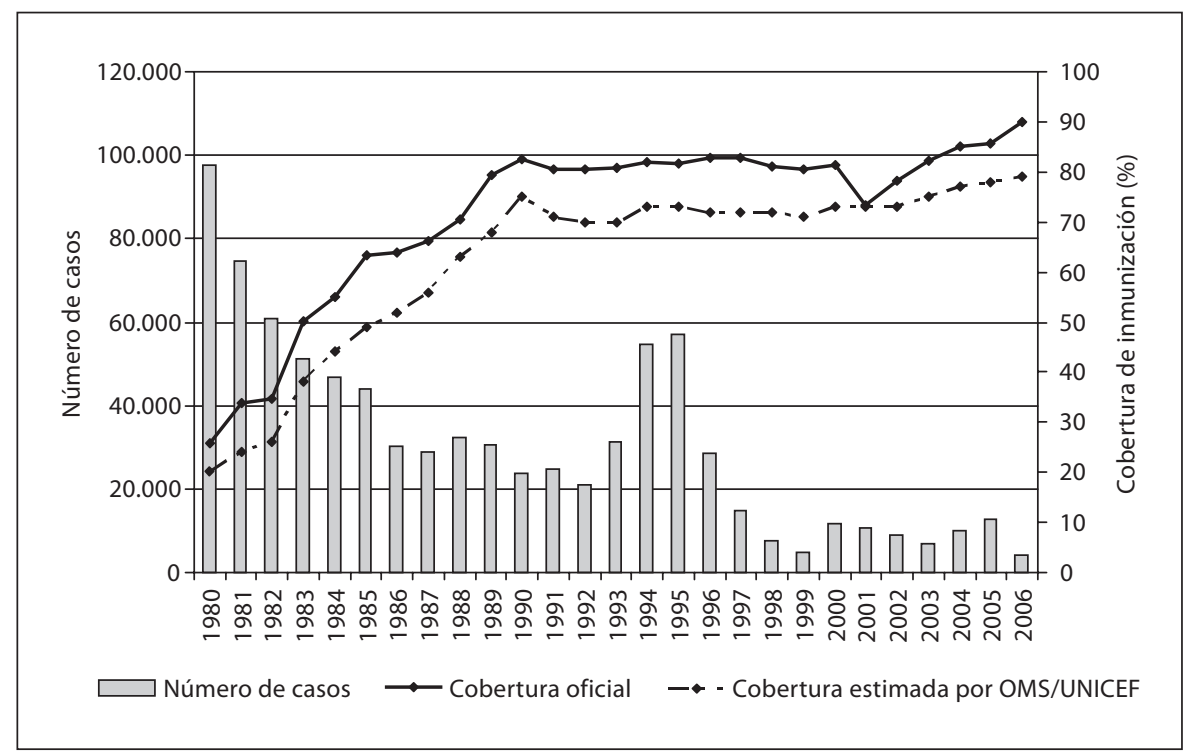

lidad sociopolítica. Esta inestabilidad converge en factores que se consideran importantes para la generación de epidemias, como el gran número de refugiados obligados a vivir en condiciones higiénicas y económicas extremadamente difíciles y, a destacar por su importancia, la falta de infraestructuras capaces de facilitar que la vacuna sea distribuida a los refugiados.

\section{Tétanos}

El tétanos es único entre las enfermedades que previenen las vacunas del EPI: se trata de una enfermedad no transmisible. A diferencia de la viruela y la poliomielitis, no puede ser erradicado. Su alta tasa de mortalidad en países tanto industrializados como en vías de desarrollo, habitualmente asociada a traumatismos en personas por lo demás sanas, particularmente durante conflictos militares, ha hecho que la disponibilidad de una vacuna sea deseable. La vacuna toxoide se desarrolló en la década de los 20. La inmunización efectiva durante la Segunda Guerra Mundial redujo la incidencia de casos de tétanos hasta alrededor de 1/30 de la incidencia reportada durante la Primera Guerra Mundial [16]. En la mayoría de los países desarrollados, el tétanos se considera actualmente una enfermedad rara debido a la mejoría del cuidado de las heridas y las tasas altas de inmunización. La distribución actual de los casos refleja una cobertura vacunal incompleta: por lo tanto, la mayoría de los casos se registra en personas ancianas.

No obstante, en el mundo en vías de desarrollo, la carga sanitaria del tétanos corresponde en gran medida a los recién nacidos. Aparte de este grupo de edad, la mayoría de los casos aparecen en chicos y adultos jóvenes no inmunizados, en quienes la tasa de tétanos declina en presencia de programas de inmunización. En 1980, las estimaciones basadas en encuestas de mortalidad sugerían que había aproximadamente un millón de fallecimientos anuales [17] debido al tétanos neonatal y de 122.000 a 300.000 muertes causadas por el tétanos no neonatal. En 1989, la Asamblea de la Salud Mundial requirió la eliminación del tétanos neonatal (y materno) en 1995. Desde entonces, la fecha límite ha sido pospuesta repetidamente. No obstante, se realizó un progreso (fig. 2): el número de muertes en el año 2000 se estimó en 200.000 y en septiembre de 2007 sólo restaban 47 países pendientes de eliminar el tétanos materno y neonatal. Para alcanzar este objetivo se utiliza un cierto número de estrategias [18]: (1) La inmunización de mujeres gestantes durante sus citas prenatales; (2) la inmunización de todas las mujeres en edad fértil a través de Actividades de Inmunización Suplementaria en ámbitos en los cuales las mujeres carecen de acceso a la vacunación sistemática o bien su acceso es limitado; (3) fomento de una asistencia calificada durante el parto.

\section{Tos ferina}

La tos ferina era en tiempos pasados una de las enfermedades infantiles más corrientes. De todas las enfermedades infecciosas pediátricas para las cuales existe una vacuna eficaz que se administra en la mayoría de los lactantes, la tos ferina es todavía la peor controlada [19]. No obstante, gracias a los extensos programas de inmunización en el mundo industrializado, que se iniciaron en la década de los 50 , se produjo una reducción espectacular $(>90 \%)$ de la incidencia de tos ferina y las epidemias importantes quedaron en gran medida eliminadas. 
Fig. 2. Incidencia anual global de tétanos neonatal reportada y cobertura con el TT2+ (como mínimo dos dosis de toxoide tetánico), 1980-2006. Reproducido con autorización de la OMS.

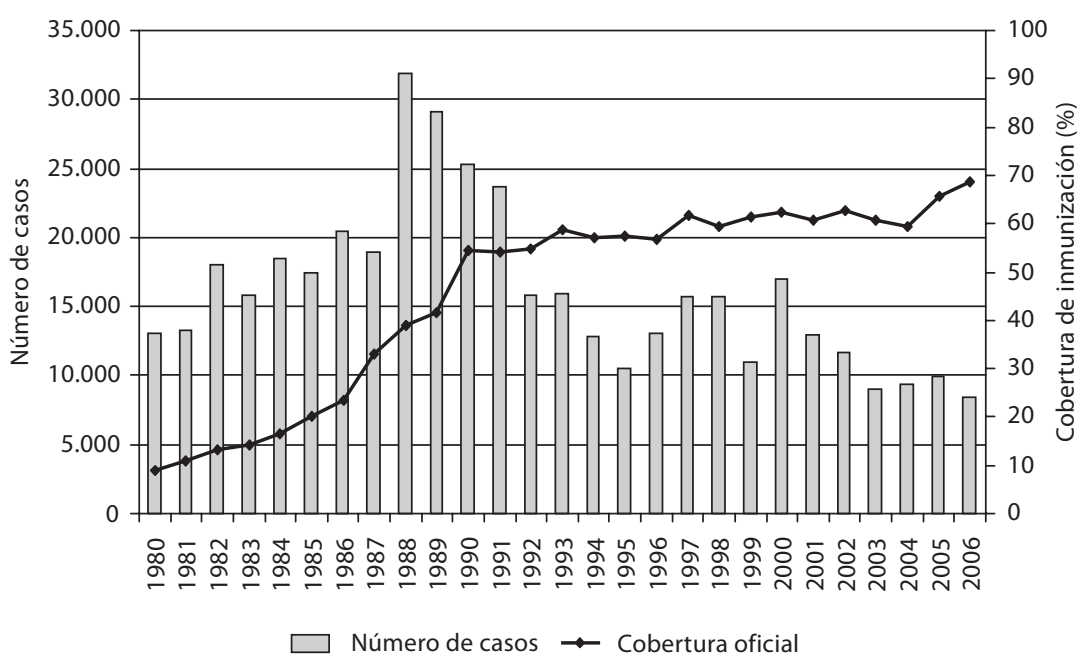

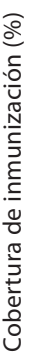

Número de casos $\rightarrow$ Cobertura oficial
La vacuna (en forma de DTeT) ha formado parte del EPI desde que este programa se inició en 1974. Desde finales de los años 80 , alrededor del $80 \%$ de todos los lactantes que habitan en el mundo entero están inmunizados. A pesar de esto, la OMS estimó la aparición en todo el mundo de 17 millones de casos en 2003 y que alrededor de 279.000 pacientes fallecieron a causa de esta enfermedad [20]. Sin embargo, las cifras de incidencia deben interpretarse con cautela: la definición de los casos y la eficiencia de los sistemas de vigilancia varían considerablemente de un país a otro.

La OMS recomienda la inmunización primaria con DTT, consistente en 3 inyecciones administradas a las 6,10 y 14 semanas de edad. La mayoría de los países se han adherido a esta pauta, aunque con variaciones menores. En numerosos países se administra una dosis de refuerzo entre 1 y 6 años después. En los países nórdicos e Italia se administran 3 dosis a las edades de 3, 5 y entre 11 y 12 meses.

La vacunación ha ejercido el impacto esperado en niños pequeños, en quienes la infección actualmente es rara. No obstante, la protección tras la vacunación contra la tos ferina se debilita al cabo de 6 a 12 años (lo mismo que la inmunidad tras la infección natural) [20]. Es probable que como consecuencia exista un desplazamiento hacia una mayor incidencia de tos ferina (tanto sintomática como asintomática) en niños de edad escolar y adultos jóvenes; del 12 al 21\% de adultos con tos persistente durante más de dos semanas pueden presentar tos ferina [20,21]. La transmisión de la infección desde estos reservorios bacterianos en grupos de mayor edad hasta lactantes muy pequeños no inmunizados [22] ha resultado en un incremento de la incidencia, incluso de tos ferina infantil, en numerosos países industrializados. Esto se halla en claro contraste con el objetivo del programa, que consiste en reducir la incidencia y la gravedad de la enfermedad en niños pequeños y especialmente muy pequeños. Para proteger a estos lactantes pequeños, muchos demasiado pequeños para ser inmunizados, la endemicidad de la infección de tos ferina podría abordarse por el refuerzo de la inmunidad en los grupos de mayor edad [22]. Esto es posible con la vacuna acelular contra la tos ferina (aT); además, la instauración de la inmunización de los adolescentes se está discutiendo actualmente en numerosos países desarrollados [19].

La incidencia creciente de tos ferina en adolescentes y adultos jóvenes se ha informado hasta la fecha en raras ocasiones en países en vías de desarrollo o en países industrializados con cobertura vacunal baja. De hecho, se ha dispuesto de una documentación muy escasa sobre la epidemiología de la tos ferina en África, Asia o Latinoamérica. En Senegal, se observó la misma tendencia durante un periodo de 12 años tras la introducción de la vacunación [23] y estudios serológicos de, por ejemplo, Taipei, Israel y Turquía, indican que niños mayores, adolescentes e incluso adultos presentan riesgo de contraer la tos ferina a pesar de un programa de inmunización de cuatro dosis [23].

La vacuna de células enteras contra la tos ferina (eT), producida en forma de DTeT por numerosos fabricantes también en países en vías de desarrollo, ha mostrado una eficacia superior al $80 \%$. Debido a un incremento de la incidencia de efectos adversos menores tras la vacunación y reacciones adversas neurológicas infrecuentes, se redujo la aceptabilidad de la vacuna en un cierto número de países industrializados durante la década de los 70. Esta situación llevó al desarrollo de la vacuna antitosferínica acelular (conocida como DTaT), de la que, si bien se espera un efecto eficaz en todas las regiones del mundo, es improbable que sea actualmente asequible en la mayoría de los países en vías de desarrollo [20]. La prioridad principal en el control de la tos ferina consiste en alcanzar una cobertu- 
ra global del $90 \%$ con las tres dosis primarias de la vacuna DTeT. Para comprender mejor si la reaparición de la tos ferina, especialmente en adolescentes y adultos jóvenes, tiene lugar también en países en vías de desarrollo, es imprescindible un perfeccionamiento de la vigilancia.

\section{Poliomielitis}

La parálisis infantil, identificada posteriormente como poliomielitis, era bien conocida incluso antes del siglo XX. En esa época, la enfermedad era endémica apareciendo la mayoría de las infecciones en niños de edades comprendidas entre 6 meses y 4 años, en quienes la meningitis no paralítica es la consecuencia más probable de la afectación del sistema nervioso central. El resultado de una higiene deficiente era la exposición constante al virus, que intensificaba una inmunidad natural y temprana en la población. En países desarrollados, durante los finales del siglo XIX y los comienzos del XX, se lograron mejoras del saneamiento comunitario, lo cual, paradójicamente, incrementaba espectacularmente la proporción de niños y adultos con riesgo de infección de poliomielitis paralítica por un mecanismo de retraso de la exposición al virus de la poliomielitis desde la lactancia hasta la vida posterior [24].

A finales del siglo XIX se observaron en Escandinavia pequeñas epidemias de poliomielitis paralítica localizada. El primer brote documentado en Suecia apareció en 1881 en la comarca de Vaesterbotten [25] y, con la llegada del siglo XX, la enfermedad llegó a ser una característica anual del patrón epidemiológico sueco. En EE.UU., la primera epidemia (descrita) apareció en 1894 [26].

Con la mejora ulterior del saneamiento se incrementó el tamaño de los brotes, que alcanzaron proporciones pandémicas en Europa, Norteamérica, Australia y Nueva Zelanda durante la primera mitad del siglo XX. En 1950, la edad pico de la incidencia de poliomielitis paralítica en EE.UU. se desplazó desde los lactantes hasta los niños de edades comprendidas entre 5 y 9 años, periodo durante el cual el riesgo de parálisis es mayor [27]. La epidemia de poliomielitis de 1952 llegó a ser el peor brote en la historia de EE.UU., con más de 3.000 personas fallecidas y 20.000 con parálisis discapacitante [28].

En 1907, el pediatra sueco Ivar Wickman [29] había clasificado los diferentes tipos clínicos de poliomielitis y llegó a sospechar que se trataba de una enfermedad infecciosa. Su teoría fue reforzada por Landsteiner (Premio Nobel en 1930, aunque por los grupos sanguíneos), que infectó a monos con material de médula espinal procedente de niños que habían fallecido a causa de la enfermedad. Finalmente, se identificaron los tres tipos en 1931 [26].

En 1948, el mismo año en que se fundó la OMS, Ender, Weller y Robbins (Premio Nobel en 1954) pudieron cultivar el virus en tejidos extraneurales. Basándose en parte en sus datos, el Dr. Jonas Salk y el Dr. Albert Sabin elaboraron sus vacunas antipoliomielíticas: una vacuna inactivada (elaborada con microbios muertos) inyectable (VPI) y una vacuna 'atenuada' oral (VPO). Salk verificó su vacuna en una de las primeras pruebas a doble ciego, controladas con placebo, que se realizaron en el mundo [30]. Después de algunos años se confirmó la eficacia de su vacuna - a pesar de la incidencia de Cutter [31] en la cual la vacuna no había sido inactivada por completo y causó cerca de 200 casos de poliomielitis - al reducir claramente el número de casos de poliomielitis, primero en EE.UU. (1955) y después en otros numerosos países. Poco tiempo después de que Salk presentase su vacuna, científicos suecos [32] presentaron la suya propia, inactivada y más segura; sin embargo, desafortunadamente, la incidencia de Cutter retrasó su empleo por varios años.

La vacuna de Sabin fue verificada internacionalmente bajo los auspicios de la OMS en 1959 cuando grupos extensos, por ejemplo, en Rusia, Holanda, México, Chile, Suecia y Japón, recibieron la vacuna [33]. Presentaba las ventajas de una administración más sencilla, un precio más bajo y la prevención no sólo de las complicaciones de la infección de poliomielitis sino también de la infección intestinal inicial. Pronto se impuso como la vacuna de elección para la mayoría de los programas de inmunización nacionales en todo el mundo. No obstante, en unos pocos países europeos, por ejemplo, Holanda y algunos países escandinavos, se siguió utilizando la VPI. Suecia introdujo la VPI en 1957 y ya en 1963 la poliomielitis había sido casi erradicada en el país. No sólo desapareció la enfermedad sino que, en general, cesó la circulación silente del virus en la comunidad. Esto motivó una gran sorpresa por parte de los partidarios de la VPO, quienes mantuvieron el punto de vista de que la VPO confería una protección inmunitaria local muy superior al intestino, previniendo de este modo la diseminación del virus poliomielítico primitivo.

Las grandes epidemias de poliomielitis causaban pánico cada verano durante las décadas de los 40 y los 50 en EE.UU. y Europa occidental. Suecia fue uno de los primeros países golpeados por la infección y presentaba también las tasas de incidencia y mortalidad más elevadas. Por último, con la introducción de la vacuna, la poliomielitis fue sometida a control. Los países en vías de desarrollo tardaron algo más en identificar a la poliomielitis como un problema muy importante.

Durante los años 70 , en un extenso número de encuestas sobre cojera (en los que se indagaba la parálisis fláccida aguda) se demostró que la poliomielitis abundaba también en numerosos países en vías de desarrollo. Esto llevó a la instauración de la inmunización sistemática con la VPO en casi todos los programas nacionales del EPI. En 1985, la Organización Panamericana de la Salud (OPS) dio comienzo a su iniciativa para erradicar la poliomielitis del continente americano. Se demostró que se trataba de un programa muy eficiente, dado que el último caso de poliomielitis en un indígena apareció en Perú en 1991. Antes de que una región pudiera declararse libre de poliomielitis, tenía que transcurrir un periodo de tres años sin presencia de la enfermedad. De este modo, en 1994 se certificó que las Américas estaban libres de poliomielitis [34]. Es inte- 
Fig. 3. Incidencia anual global de poliomielitis reportada y cobertura de Pol3, 1980-2006. Reproducido con autorización de la OMS.

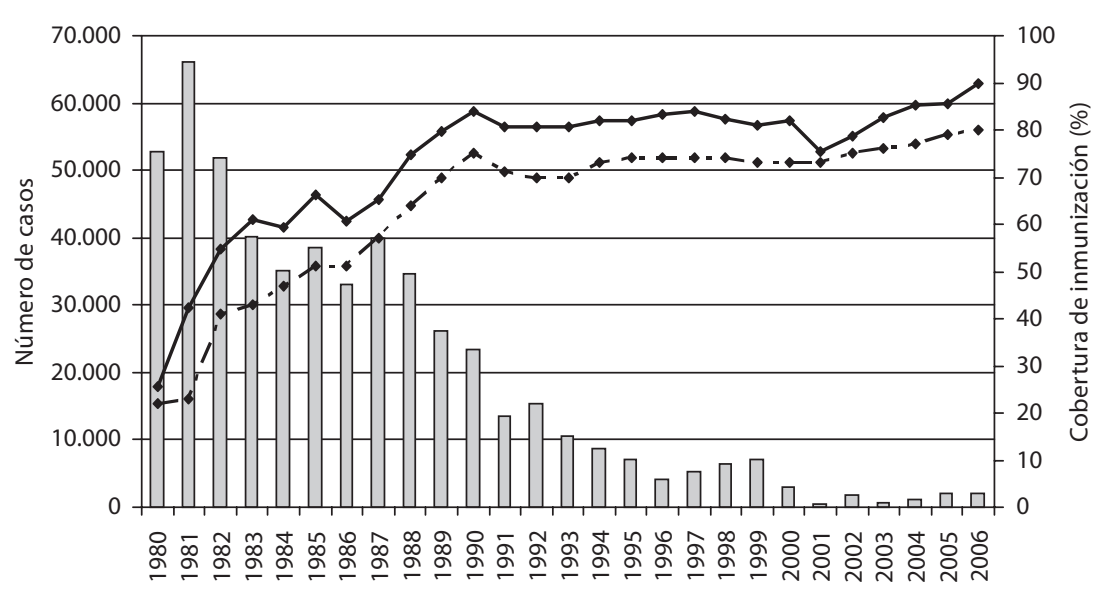

Número de casos

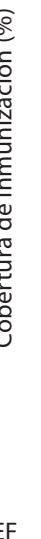

resante destacar que desde 1999, Norteamérica ha regresado a la utilización de la VPI debido al riesgo de que la vacuna de virus vivos atenuados se pudiera revertir y recobrar su propiedad de causar parálisis: poliomielitis paralítica asociada a la vacuna, una consecuencia inevitable del uso de la VPO.

En 1988, el virus poliomielítico era endémico en más de 125 países, llegando a causar parálisis a más de 1.000 niños cada día [26]. El mismo año, los resultados ya positivos de la OPS convencieron a la Asamblea de Salud Mundial a pasar a resolución la erradicación de la poliomielitis en el año 2000. Esta declaración se basó en gran medida en el conocimiento de que se habían puesto a disposición fondos del Rotary International y su campaña lanzada en 1987 para recaudar 120 millones de dólares (\$ EE.UU.) con el fin de luchar contra la poliomielitis. En el momento en que se certifique que el mundo está libre de poliomielitis, sus donaciones serán cinco veces más altas [26].

Dentro del programa EPI, la VPO se administra habitualmente en cuatro dosis antes de que el niño cumpla su primer año. Para 1990 se inmunizó a casi el 80\% de los niños nacidos cada año, registrándose un descenso considerable de la incidencia de la enfermedad (fig. 3).

Con objeto de seguir mejorando la situación, se iniciaron los Días Nacionales de Inmunización (NID): estas campañas de inmunización masiva estaban encaminadas a complementar, no a sustituir, la inmunización sistemática. El objetivo consistía en interrumpir la circulación del virus poliomielítico inmunizando a cada niño menor de 5 años con 2 dosis de VPO, intercalando un intervalo de un mes entre las dosis, independientemente de la situación de inmunización previa. De este modo, cada niño perteneciente al grupo de edad más vulnerable quedaba protegido frente a la poliomielitis al mismo tiempo, es decir, el virus carecía de hospedador en el cual sobrevivir. Voluntarios con un entrenamiento mínimo pueden actuar como vacunadores, sirviendo como ejemplo NID en India, donde dos millones de voluntarios inmunizaron a 134 millones de niños en un solo día [26].

China sufrió un extenso brote entre 1989 y 1990 con 5.000 casos cada año, que culminó por último en la realización de NID en 1994, en los cuales fueron inmunizados 80 millones de niños durante un corto periodo de tiempo [26]. Dos años después se identificaba el último caso de poliomielitis en China. India siguió el ejemplo con sus primeros NID en 1995.

Las actividades en la región del Pacífico Occidental de la OMS permitieron que esta región recibiera el certificado de liberación de poliomielitis en el año 2000; el último caso se registró en Camboya en 1997. La región del Pacífico Occidental de la OMS incluye a China, así como a Indonesia, con más de 1/4 de la población global total [35].

A menudo son necesarios 3 a 5 años de NID repetidos (en zonas endémicas, 7 a 8 ciclos por año) para erradicar la poliomielitis; sin embargo, algunos países necesitan más tiempo, especialmente aquéllos donde la cobertura de la inmunización sistemática es baja. India y China son buenos ejemplos de actividades de países individuales. No obstante, el virus poliomielítico no respeta fronteras y, por lo tanto, los países vecinos están tratando de 'sincronizar' sus NID. Este enfoque se utilizó en 1995 en 19 países de Europa del Este y Asia Central (Operación MECACAR: Mediterráneo, Cáucaso, Repúblicas Asiáticas Centrales y Rusia), con la inmunización de 56 millones de niños [26]. Se emprendieron campañas multinacionales similares en África Occidental y África Central (en el año 2000, 76 millones y en 2004, 63 millones de niños) y a lo largo de la frontera entre Afganistán y Pakistán y otras zonas en guerra y conflicto, donde se negoció una tregua que cubriera unos pocos días de actividades de inmunización [26].

En el año 2000 se contabilizó un récord de 550 millones de niños, casi 1/10 de la población mundial, receptores de VPO [26], y en el mismo año 719 casos de virus poliomielítico natu- 
Tabla 2. Casos confirmados de poliomielitis, causados por el virus natural en países endémicos y no endémicos en los años 2000 a 2007 [26]

\begin{tabular}{|c|c|c|c|c|c|c|c|c|}
\hline & 2000 & 2001 & 2002 & 2003 & 2004 & 2005 & 2006 & 2007 \\
\hline \multicolumn{9}{|c|}{ Casos en países actualmente endémicos (noviembre de 2007) } \\
\hline India & 265 & 268 & 1.600 & 225 & 134 & 66 & 676 & 873 \\
\hline Nigeria & 28 & 56 & 202 & 355 & 782 & 830 & 1.122 & 285 \\
\hline Pakistán & 199 & 119 & 90 & 103 & 53 & 28 & 40 & 32 \\
\hline Afganistán & 27 & 11 & 10 & 8 & 4 & 9 & 31 & 17 \\
\hline \multicolumn{9}{|c|}{ Total casos en países endémicos } \\
\hline & 702 & 475 & 1.915 & 732 & 999 & 943 & 1.869 & 1.207 \\
\hline \multicolumn{9}{|c|}{ Total casos en países no endémicos } \\
\hline & 17 & 8 & 3 & 52 & 256 & 1.036 & 125 & 106 \\
\hline Países & 23 & 15 & 9 & 15 & 18 & 16 & 17 & 12 \\
\hline Países endémicos & 20 & 10 & 7 & 6 & 6 & 6 & 4 & 4 \\
\hline
\end{tabular}

Datos de la sede central de la OMS el 21 de mayo de 2008.

ral representaron una reducción del 99\% desde el inicio del programa en 1988 (tabla 2).

En Europa, apenas 400 casos en el año 1990 se redujeron a sólo 200 en 1992. En dicho año, un brote de poliomielitis en los Países Bajos (hasta donde el virus se había propagado desde India a través de Oriente Medio) apareció en un grupo que, por motivos religiosos, se negó a ser inmunizado y, en consecuencia, el virus de esta epidemia se propagó hasta Canadá [26]. En 1993 aparecieron pequeñas epidemias en Azerbaiján y Ucrania, en tanto que Albania, que había permanecido libre del virus poliomielítico natural durante 18 años, presentó en 1996 un brote que se propagó a los países vecinos [26]. Finalmente, Turquía sufrió el último caso de poliomielitis indígena en Europa en 1998; en 2002 se certificó que la región europea de la OMS (51 países) estaba libre de poliomielitis [36].

Aunque no hay duda de que la campaña de poliomielitis para la erradicación del virus resultó muy satisfactoria, no concluyó en el año 2000 tal como se había planeado. La fecha de la conclusión tuvo que posponerse repetidamente.

Hay cierto número de explicaciones que dan cuenta de este retraso: la infección por el virus poliomielítico causa síntomas en el sistema nervioso central sólo en una pequeña fracción de las personas infectadas, que es de aproximadamente 1 caso por 100 a 200 infectados. En consecuencia, es difícil seguir y controlar la diseminación masiva del virus a partir de numerosas infecciones intestinales, habitualmente silentes.

También se suscitaron algunos problemas con las vacunas existentes: ambas vacunas tienen que administrarse en dosis repetidas y los tres tipos de virus poliomielítico compiten entre sí. Para obtener una multiplicación efectiva de los tres tipos, las vacunas tienen que administrarse como mínimo tres veces. Otros virus entéricos pueden competir también con el virus de la vacuna: la vacuna viva atenuada puede causar problemas en zonas donde la higiene es deficiente. Otro problema relaciona- do con la vacuna viva atenuada es la posibilidad de reversión. Los virus de poliomielitis derivados de la vacuna (VPDV) pueden (1) causar brotes de poliomielitis en zonas con tasas bajas de cobertura de la VPO (VPDVc 'circulante') y (2) multiplicarse durante años en personas inmunodeficientes (VPDVi). Cuando el virus de la vacuna se propaga a numerosas personas no inmunizadas y durante este proceso revierte al virus poliomielítico natural, puede causar parálisis en personas no inmunizadas. Puede prevenirse la aparición de VPDVc por medio de una buena cobertura vacunal. Por su parte, los VPDVi pueden aparecer cada vez que una persona con inmunodeficiencia primaria se exponga a la VPO. El único modo de prevenir nuevas infecciones por VPDVi es suspender la administración de la VPO.

El año 2003 parecía prometedor (tabla 2), al censar sólo 784 nuevos casos registrados, casi la mitad en Nigeria. A pesar de la realización de grandes esfuerzos continuados, resultó evidente que los últimos restos de poliomielitis serían difíciles de eliminar. No obstante, el número de países donde la poliomielitis es endémica se ha reducido actualmente a cuatro: Afganistán, Pakistán, India y Nigeria; estos cuatro países actúan como fuente de infección para la reintroducción en países que anteriormente habían sido declarados libres de poliomielitis (fig. 4).

En agosto de 2003, cierto número de estados septentrionales de Nigeria suspendieron las campañas de inmunización de poliomielitis tras los temores suscitados por algunas cifras públicas referentes a la seguridad de la vacuna antipoliomielítica. Subsecuentemente, se produjo un nuevo brote originado en el estado de Kano, que reinfectó zonas previamente libres de poliomielitis dentro de Nigeria, así como ocho países previamente libres de poliomielitis en África Occidental y África Central (tabla 2, fig. 4) [37]. Cuando se reanudaron las actividades de inmunización en Nigeria septentrional en julio de 2004, se rea- 


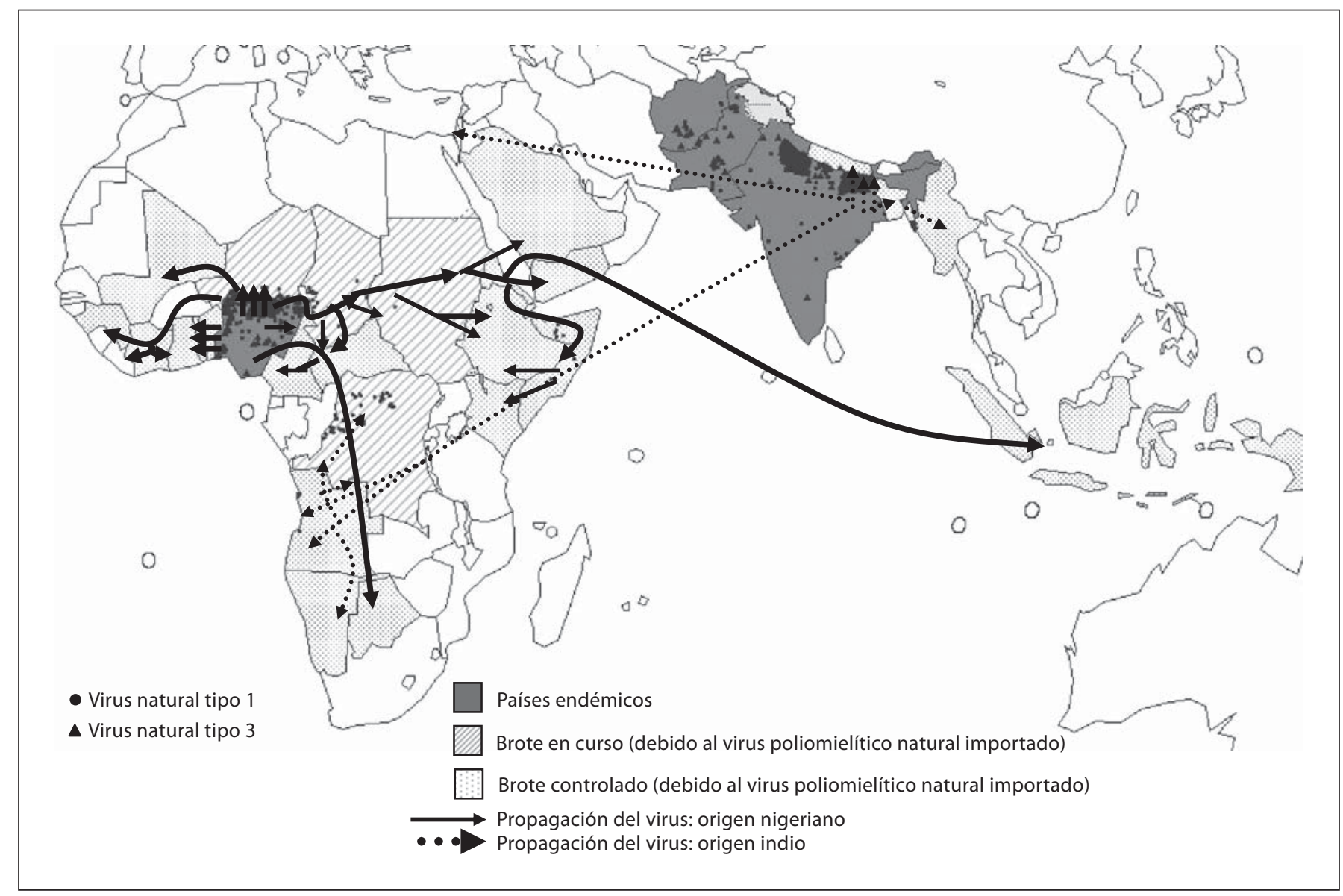

Fig. 4. Propagación del virus poliomielítico natural entre 2003 y 2007 (excluyendo virus detectados por vigilancia medioambiental y virus de poliomielitis derivados de vacunas). Países endémicos: hacia el 1 de enero del 2006, Egipto y Níger fueron reclasificados de endémicos a no endémicos. Reproducido con autorización de la OMS.

lizó la campaña multinacional más extensa hasta la fecha, en la que participaron más de un millón de vacunadores en 23 países de África Oriental y África Central y se inmunizó a más de 80 millones de niños. Aunque el número de casos siguió incrementándose en Nigeria, en 2007 pareció haberse logrado una mejora (tabla 2). Nigeria sigue siendo el único gran riesgo para alcanzar el objetivo de la erradicación de la poliomielitis [38]. Existe una transmisión generalizada debido a lagunas en la inmunidad de la población, y en varios de los estados septentrionales más del $20 \%$ de los niños menores de 5 años no han recibido ni siquiera una dosis única de VPO [39].

En el año 2002, India sufrió una gran epidemia con 1.600 casos. No obstante, en 2005, con un incremento espectacular, tanto de la calidad como de la cantidad de campañas de inmunización, India pudo reportar el menor número de casos nunca registrado (66). Uttar Pradesh occidental sufrió un brote en 2006 al que contribuyó la elevada densidad demográfica y la higiene deficiente. También es posible que la gran prevalencia de infecciones entéricas pueda interferir con la respuesta inmunitaria y explicar la reducida eficacia de la VPO en comparación con otras partes de India [38]. Como consecuencia, la mayoría de los niños de Uttar Pradesh recibieron más de 12 dosis de vacuna antes de su segundo cumpleaños para obtener la inmunidad [39].

En Pakistán, la transmisión queda restringida a áreas en donde la seguridad se ve comprometida, con una situación similar a la que se observa en Afganistán meridional donde se produjo un brote significativo en 2006. En las regiones fronterizas entre los dos países, la inestabilidad política y los conflictos armados dificultan en gran medida las actividades de inmunización [38].

En la mayoría de los 24 países, los brotes fueron suspendidos con éxito en 2005 (con un coste superior a 450 millones de dólares EE.UU.) (tabla 2). No obstante, las mayores epidemias en países individuales de los últimos años, que afectaron a Yemen e Indonesia, no pudieron detenerse por completo hasta 2006. 
El virus poliomielítico de tipo 2 no ha sido detectado desde 1999 y, en consecuencia, actualmente se utilizan vacunas monovalentes con el tipo 1 o el tipo 3. En estudios se ha demostrado que la VPOm1 monovalente es tres veces más eficaz que la VPO trivalente en la protección de niños frente a la poliomielitis [37]. Se ha utilizado con éxito en zonas endémicas como Uttar Pradesh. La VPOm3 ha sido utilizada análogamente en zonas en las que predomina el serotipo 3 .

Debido a estas epidemias generalizadas entre 2003 y 2006 en países anteriormente libres de poliomielitis, surgió una actitud escéptica acerca de la factibilidad de la erradicación. Puede que el 'control efectivo' continuado (definido como el mantenimiento de menos de 500 casos de poliomielitis/año indefinidamente) sería más económico y más factible [26]. No obstante, actualmente se dispone de nuevas herramientas (diagnósticos rápidos perfeccionados y vacunas monovalentes más potentes) que han contribuido a la reducción considerable de los casos de poliomielitis en 2007 (tabla 2). En 2008, la erradicación total sigue siendo el objetivo. El éxito depende de los cuatro países restantes, donde son necesarios abordajes individualizados para cada uno de ellos debido a las diferentes problemáticas operativas.

Si el mundo eventualmente fuera certificado como libre de poliomielitis, ¿cómo debería procederse a continuación? El riesgo de reaparición es todavía una realidad. Uno de los problemas consiste en la extensa proporción de infecciones subclínicas que facilitan una diseminación silente del virus. Otro problema es la posibilidad, mencionada anteriormente, de que el virus de la vacuna viva atenuada (VPO) pueda revertirse y causar parálisis: un [1] caso entre 3 millones de vacunados y como mínimo 9 pequeños brotes reportados (causados por VPDVc) con un total de 200 lactantes paralizados [26]. Será crítico mantener la inmunidad poblacional a largo plazo para prevenir la circulación de virus que reaparecen. En septiembre de 2006, el Comité Asesor sobre Erradicación de la Poliomielitis impartió las siguientes recomendaciones para el cese definitivo de la inmunización sistemática con VPO [40]: (1) Confirmación de la interrupción y la contención globales del virus poliomielítico natural; (2) uso de vigilancia altamente sensible; (3) establecimiento de reservas de VPO monovalente para responder al virus poliomielítico circulante reaparecido; (4) mantenimiento de una cobertura nacional superior al 90\% de VPI en todos los países con instalaciones de virus poliomielíticos; estas instalaciones (que podrían realizar funciones esenciales de referencia e investigación) serían menos de 20 en todo el mundo; (5) cese global sincrónico del uso de la VPO para la inmunización sistemática; (6) contención de las cepas Sabin del virus poliomielítico.

No obstante, una campaña tan prolongada sería costosa: 400 millones de dólares EE.UU. por año hasta la erradicación del virus y varios años subsiguientes. A pesar de ello, la tarea tiene que concluir; el mundo se encuentra sólo a pocos pasos de librarse de la poliomielitis para siempre.

\section{Sarampión}

La infección por el virus del sarampión sigue al paludismo en términos del número de personas que fallecen cada año como consecuencia de complicaciones de una enfermedad infecciosa [41].

El primer texto sobre sarampión del siglo X fue redactado por el médico persa Rhazes. Durante muchos siglos llegó a suponerse que el sarampión y la viruela estaban estrechamente relacionados: 'El sarampión debe ser más temido que la viruela' [42]. En el siglo XVII se estableció la distinción entre ambas enfermedades y en 1758, Francis Home identificó la naturaleza infectiva del sarampión. Tras la epidemia que tuvo lugar en 1846 en las islas Feroe, la epidemiología fue mucho mejor entendida [42]. En 1954, Enders y Peebles procedieron a aislar el virus en cultivos tisulares, y la vacuna fue autorizada en 1963.

El sarampión aparece en ciclos epidémicos, y en países desarrollados suele iniciarse en grandes ciudades, los reservorios del sarampión donde permanece endémico. Seguidamente se disemina a la campiña, en cuyo medio la transmisión podría extinguirse después de una epidemia, por lo que para que se inicie la siguiente temporada epidémica el virus tiene que ser reintroducido.

Antes de la introducción de la vacuna, el riesgo de infección en países desarrollados era el más alto en niños de edad escolar. Por otra parte, en numerosos países en vías de desarrollo, la infección aparecía a una edad mucho más temprana. En África se preveía que el 100\% de los niños menores de 4 años presentaran sarampión. En este continente, los niños son expuestos en gran medida a la comunidad en una edad temprana (por lo menos en comparación con niños de países desarrollados) y conllevan un riesgo elevado de contraer la infección. Además, su inmunidad a menudo subóptima, debido a, por ejemplo, una nutrición deficiente (vitamina A) y la pérdida rápida de anticuerpos transferidos por vía placentaria, explica por qué la infección de sarampión ataca tan precozmente y es a menudo tan grave en los países en vías de desarrollo. También puede ser importante el hacinamiento, que propicia una dosis elevada del virus [43].

En el momento de la introducción de la vacuna aumentó el intervalo entre las epidemias al tiempo que se redujo el tamaño de las mismas. Se observó un número relativamente mayor de casos en niños de mayor edad que o bien nunca habían sido vacunados o no respondían a la vacunación. Cuando aumenta la cobertura y disminuye la transmisión vírica, incluso las personas no vacunadas presentan un menor riesgo de infección.

Se ha estimado que el umbral para la inmunidad de rebaño se obtiene con una cobertura de vacunación del 93 al 95\% [44]. Cuando esta inmunidad se mantiene, la transmisión del virus se extinguirá y el sarampión quedará eliminado. Sin embargo, un país puede tener casos importados de otros países donde el sarampión es todavía endémico. No obstante, en una población correctamente inmunizada, dichos casos no correspon- 
Fig. 5. Incidencia anual global de sarampión reportada y cobertura de la vacuna contra el sarampión, 1980-2006. Reproducido con autorización de la OMS.

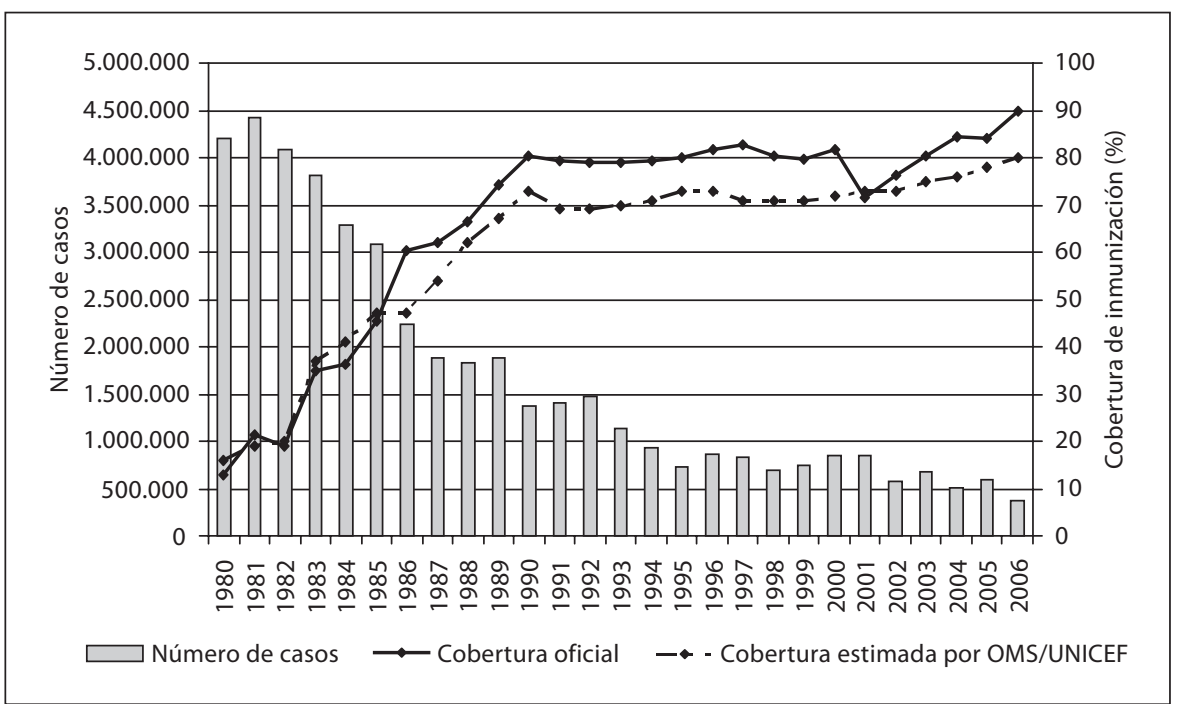

derán a más de unos pocos casos secundarios. La eliminación del sarampión en todos los países (al mismo tiempo) se denomina erradicación global.

En el mundo occidental, una dosis única de vacuna administrada entre 12 y 18 meses de edad induce inmunidad en alrededor del 95\% de los vacunados. Cuando el 5\% que no responde a la primera dosis recibe una segunda, responde más del 95\% y, en consecuencia, con una cobertura del 95\% con dos dosis puede alcanzarse el objetivo para una inmunidad de rebaño [41].

Con respecto a los países en vías de desarrollo se recomienda la inmunización ya a los 9 meses de edad debido a la elevada morbilidad y mortalidad entre los lactantes. En esta edad, la seroconversión se produce en sólo el 85\% [41]. Con esta tasa de conversión y una cobertura del 90\% (cifra bastante optimista en numerosos países), la inmunidad alcanzaría únicamente al 77\% de los niños. Incluso la administración de una segunda dosis en una edad en la que la seroconversión es del 95\%, administrada en el marco de los servicios sanitarios sistemáticos con sólo una cobertura del 90\% (o inferior), no mejoraría demasiado la situación con respecto a la inmunidad de rebaño. La respuesta al problema podría consistir en campañas masivas: si durante una campaña el $90 \%$ de los niños no vacunados previamente reciben su primera dosis y el $90 \%$ de los vacunados previamente reciben su segunda dosis, la inmunidad de la población será superior al 95\% necesario [41, 45].

La vacuna se introdujo gradualmente a través del EPI a partir de 1974 en casi todos los países del mundo, basándose en las recomendaciones de OMS/UNICEF de que debe administrarse una dosis de vacuna a los 9 meses de edad como mínimo al $80 \%$ de los niños en todos los países. Hacia finales de la década de los 80, la cobertura global se aproximaba al 80\% (fig. 5) si bien, seguidamente, el interés entre los donantes se redujo y, en consecuencia, la cobertura se estabilizó en el 70 al 80\% duran- te los años 90. El problema no residía únicamente en que la baja cobertura mantenía elevado el número de casos de sarampión, sino, como ya se ha mencionado, los lactantes pequeños contraían habitualmente la infección y la mortalidad de los casos era elevada. ¿Cómo podemos proteger a estos lactantes pequeños?

¿Podrían ser vacunados los lactantes a una edad incluso más temprana? Para superar el efecto neutralizante de los anticuerpos maternos se elaboró una vacuna contra el sarampión de alto valor y se administró a los 4-6 meses de edad en un cierto número de países africanos. Aunque la vacuna era más inmunógena que la vacuna estándar y protegía frente al sarampión en ese grupo de edad, se asociaba a un aumento imprevisto del número de fallecimientos (por diarrea, neumonía y paludismo) entre las niñas. Estas vacunas no se utilizan actualmente [46].

La OPS elaboró otro abordaje. Hacia finales de siglo, numerosos países industrializados habían seguido los ejemplos de Suecia y Finlandia e instaurado una segunda dosis sistemática. En 1987, Cuba realizó una campaña de vacunación masiva en todo el país, de una sola vez, con el objetivo de inmunizar a todos los niños entre 9 meses y 14 años independientemente de su historia de vacunaciones previas. La idea era que debía reducirse la transmisión entre niños mayores, con lo cual se evitaría también la transmisión a los lactantes. La estrategia, que resultó satisfactoria en Cuba, se introdujo en el resto del continente americano y posteriormente en el resto del mundo [47]. Consta de 3 componentes: (1) Mantenimiento de una cobertura superior al $90 \%$ en la inmunización sistemática a los 9 hasta los 12 meses de edad en todos los distritos; (2) realización de una vacunación masiva de una sola vez en todos los niños de 1 a 14 años de edad; (3) repetición de campañas masivas cada 3 a 5 años para todos los niños entre 1 y 5 años independientemente de sus antecedentes patológicos y las vacunaciones pre- 
vias. Por supuesto, es también importante la vigilancia efectiva de los casos de sarampión y la buena asistencia clínica de los pacientes afectados de esta enfermedad. En el hemisferio occidental, el resultado de esta estrategia fue una declinación superior al 99\% de casos declarados durante la década de los 90. En 2002, Venezuela y Colombia eran los únicos países con brotes extensos y en septiembre de 2003 la OPS anunció que el hemisferio occidental había quedado liberado de sarampión endémico durante 10 meses consecutivos [41].

En 2002, en la Sesión Especial sobre la Infancia de la Asamblea General de la ONU se estableció el objetivo de reducir la mortalidad por sarampión en todo el mundo en un 50\% desde 1999 hasta finales de 2005. Las estimaciones recientemente efectuadas indican que durante el periodo mencionado se produjo realmente una reducción gratificante del $60 \%$, principalmente a través de actividades en la región africana [48]. Estas estimaciones son respaldadas por informes de países donde se han puesto en práctica las estrategias de vacunación recomendadas. Se observó una reducción del 92\% de casos de sarampión comunicados en 19 países africanos. En uno de los países más deprimidos del mundo, Malawi, el número de casos de sarampión descendió en picada de 7.000 en 1997 a sólo 2 casos en 1999 [49]. Camboya y Vietnam comunicaron una declinación de casos de 12.237 y 16.512 a 264 y 410, respectivamente, durante un periodo de 5 años [48].

OMS y UNICEF, con sus asociados, poseen actualmente una perspectiva con respecto al periodo entre 2006 y 2015: una cobertura del $90 \%$ en todos los distritos y una reducción del $90 \%$ de la mortalidad por sarampión en todo el mundo entre 2000 y 2010. Países extensos como India, Pakistán e Indonesia tienen todavía una elevada carga de casos de sarampión y fallecimientos por esta enfermedad, por lo que en estas regiones las actividades descritas anteriormente tienen que ser puestas en práctica plenamente $[48,49]$.

En países donde se ha alcanzado una cobertura elevada de vacunación sistemática, la segunda oportunidad para la inmunización del sarampión puede plasmarse, por el contrario, mediante una vacunación sistemática de 2 dosis contra el sarampión, donde la segunda dosis se administra entre 12 y 18 meses de edad o en el momento de iniciar la escolarización. Esta ha sido la pauta introducida en la mayoría de los países industrializados, especialmente después de haber experimentado la reaparición del sarampión. Así aconteció en EE.UU. entre 1989 y 1991, con más de 50.000 casos reportados y 123 fallecimientos; el motivo más importante del brote fue una cobertura baja de vacunación [41]. A mediados de los 90, Canadá, con un programa de una sola dosis, sufrió un brote de sarampión en niños mayores y adultos jóvenes [41]. La cobertura de la vacuna fue superior al $90 \%$ (pero sin alcanzar el $100 \%$ ), de modo que la pequeña proporción de niños que siguieron siendo vulnerables, bien sea como consecuencia del fallo de la vacunación primaria o por no haber recibido la primera dosis, mostró una acumulación en el curso del tiempo. Cuando se introdujo el virus, el grupo fue suficientemente extenso para permitir la transmisión, por lo que apareció el brote. Las experiencias de otros países (Corea del Sur, Brasil y Sri Lanka) han confirmado que una estrategia de dosis única no puede prevenir brotes episódicos de sarampión [41].

Los brotes en Europa también siguen siendo corrientes, si bien los fallecimientos son infrecuentes en la actualidad. En 2004, en la región europea de la OMS se reportaron más de 29.000 casos. La controversia sobre la seguridad de la vacuna contra el sarampión a finales de los años 90 causó una declinación de la captación en numerosos países. En Londres, una proporción tan elevada como el $44 \%$ de los niños preescolares mostraron vulnerabilidad al mismo tiempo, lo que alentó la puesta en práctica de campañas de vacunación. Aunque la cobertura mejoró, era todavía (a comienzos de 2007) alarmantemente baja; por ejemplo, en Londres con un $77 \%$ para la primera dosis y un $52 \%$ para la segunda $[50,51]$. En el Reino Unido se observaron extensos brotes que se propagaron a otros países europeos. Para citar otros ejemplos, en el año 2000 los Países Bajos e Irlanda sufrieron brotes con 3.300 y 1.200 casos, respectivamente, y en cada uno de estos países fueron hospitalizadas más de 100 personas y hubo que lamentar 2 a 3 fallecimientos. En 2006, la región federal de Renania del NorteWestfalia (Alemania) sufrió más de 1.000 casos, de los que el $15 \%$ tuvieron que ser hospitalizados [52].

¿Se puede erradicar el sarampión? ¿No sería más rentable mantener una cobertura de inmunización elevada y prevenir la mortalidad por sarampión? Los beneficios consistirían en los ahorros derivados del tratamiento de pacientes con sarampión y los ahorros derivados del cese de la vigilancia y la vacunación del sarampión. No obstante, cierto número de factores abogan a favor de la erradicación: (1) No existe un reservorio animal; (2) no ha sido descrita una diseminación crónica del virus (como es el caso de la poliomielitis, el herpes o la hepatitis vírica); (3) se dispone de pruebas diagnósticas satisfactorias; (4) la vacunación es segura y eficaz; (5) ha cabido la posibilidad de interrumpir la transmisión vírica en extensas zonas geográficas.

Sin embargo, también hay problemas: el incremento de la densidad demográfica en las áreas metropolitanas requiere una cobertura elevada; los actos de guerra y terrorismo en curso impiden actividades de inmunización; el incremento de los viajes internacionales facilita la difusión de los virus. Incluso si se pudiera interrumpir la transmisión del virus del sarampión en todo el mundo, persistiría todavía la amenaza de una reintroducción a partir de accidentes de laboratorio o armas biológicas. También se ha descrito que la inmunización del sarampión reduce sobre todo la mortalidad infantil, no sólo a través del impedimento del sarampión sino de la protección frente a procesos distintos del sarampión [53]. Lo más probable es que tengamos que continuar para siempre, como mínimo, con la pauta de una dosis. 


\section{Resto de vacunas del EPI}

La OMS ha recomendado la inclusión de las vacunas siguientes en la inmunización sistemática de los lactantes:

1988: Vacuna contra la fiebre amarilla en países con riesgo de esta enfermedad.

1992: Vacuna antihepatitis B, globalmente.

2006: Vacuna contra Haemophilus influenzae de tipo b (Hib), globalmente, 'a menos de que existan pruebas contundentes a favor de una carga patológica baja'.

2006: La vacuna antineumocócica conjugada 'debe ser considerada para su inclusión en países donde la enfermedad neumocócica invasiva se tiene por un problema de salud pública y donde los serotipos vacunales se equiparan a los serotipos locales más importantes'.

\section{Fiebre amarilla}

La fiebre amarilla, una enfermedad epidémica en otra época muy temida, ha estado bajo control durante casi 40 años a través de campañas de vacunación masivas. No obstante, desde finales de la década de los 80 , la enfermedad ha regresado con fuerzas renovadas al África Subsahariana, América del Sur y América Central. Usualmente la enfermedad causa casos esporádicos o pequeños brotes, pero teniendo en cuenta que el vector mosquito apropiado está regresando a ciudades donde había sido erradicado anteriormente existe también el riesgo de la forma devastadora de epidemias urbanas. También en Asia existen vectores apropiados. Las campañas masivas de vacunación preventiva están complementando actualmente la inmunización sistemática de los lactantes [54].

\section{Hepatitis $B$}

Un total de 350 millones de personas son portadoras crónicas del virus y entre 500.000 y 700.000 fallecen cada año por insuficiencia hepática (cirrosis o cáncer) [55]. La vacuna, disponible desde 1982, es 'la primera vacuna contra un cáncer humano importante', es muy segura y confiere protección a alrededor del 95\% de la población sana, especialmente lactantes y niños. Un $85 \%$ de todos los países han incluido la vacuna en sus programas y se han administrado más de un billón de dosis. La prevalencia de la infección por el virus de la hepatitis $\mathrm{B}$ (VHB) y el estado de portador crónico se han reducido de un modo efectivo. A título de ejemplo mencionaremos que la tasa de portador crónico en niños de Taiwán se ha reducido del 9,8\% antes del programa de inmunización contra el VHB (1984) al 0,7\% 15 años después del programa (1999). La incidencia de carcinoma hepatocelular infantil ha declinado también en Taiwán, pero sólo del 0,54 al 0,20 (por 100.000 niños) [56]. Si bien la vacuna es muy eficaz en la prevención de la transmisión horizontal, el programa actual de inmunización contra el VHB no puede interrumpir por completo la transmisión materna. La ausencia de inyecciones de inmunoglobulina de hepatitis B para lactantes de madres altamente infectivas es una causa importante de este fallo (relativo). El coste de la in- munoglobulina puede ser prohibitivo en numerosos países; no obstante, el coste de la vacuna antihepatitis B (que cuando fue introducida costaba 100 dólares EE.UU. por dosis en países industrializados) es actualmente similar al de las vacunas tradicionales del programa EPI, es decir, 0,25 dólares EE.UU. por dosis.

\section{Haemophilus influenzae de tipo $b$}

Durante la década de los 90 se introdujo la vacuna Hib en los servicios de inmunización sistemática de lactantes en la mayoría de los países industrializados, quedando prácticamente eliminadas las enfermedades causadas por el Hib (neumonía y meningitis). En general, se administra una serie primaria de 3 dosis al mismo tiempo que la DTT. En el Reino Unido se utilizó una pauta acelerada de 2-3-4 meses. A pesar de la cobertura favorable de la vacuna, de 1999 a 2002 se observó un incremento de la enfermedad invasiva, lo que dejó entrever la necesidad de un refuerzo en el segundo año de vida [57].

Los países en vías de desarrollo se han mostrado indecisos ante la introducción de esta vacuna debido a su precio relativamente elevado y a los problemas relacionados con el establecimiento de la carga de la enfermedad por Hib en zonas con vigilancia deficiente. No obstante, con el apoyo financiero de la Alianza Global para Vacunas e Inmunización (GAVI), más de 20 países en vías de desarrollo han gestionado actualmente la introducción de la vacuna. Datos procedentes de Kenia, donde la vacuna se introdujo en 2001, indican que la vacuna contra el Hib es una intervención sumamente rentable y que podría ahorrar costes si el precio de la vacuna se situara por debajo de la mitad de su nivel actual [58].

\section{Infecciones neumocócicas}

Se estima que las infecciones neumocócicas (neumonía y meningitis) matan cada año a 1,3 millones de niños menores de 5 años. Casi todas estas muertes se producen en los países más pobres del mundo. Actualmente (2008) sólo existe una vacuna aprobada para uso en lactantes y niños pequeños, una vacuna conjugada en la que se incluyen los 7 serotipos más corrientes en EE.UU. (se hallan todavía en fase de desarrollo las vacunas con 10 y 13 serotipos, respectivamente). La vacuna disponible se introdujo en EE.UU. en el año 2000 y ha permitido un rápido descenso de la tasa de infecciones invasivas causadas por los tipos vacunales, no sólo en niños vacunados sino también en niños y adultos no vacunados, lo que demuestra la inmunidad de rebaño [59].

La GAVI, así como otras asociaciones públicas y privadas, desarrolla una gran actividad con respecto al suministro de vacunas antineumocócicas al mundo en vías de desarrollo. Aunque sus esfuerzos sinceros son loables, se recomendó a los Ministerios de Sanidad que antes de decidir sobre la introducción de la vacuna consideraran un cierto número de problemas relacionados con su empleo. Un ámbito de preocupación es la observación del incremento de la enfermedad de serotipos no 
vacunales, además de haberse reportado un aumento de la resistencia a los antibióticos de estas 'cepas sustitutivas'. La distribución de los serotipos varía también de un país a otro: se cree que los serotipos 1 y 5 son conjuntamente responsables del $29 \%$ de los casos de enfermedad neumocócica invasiva en India; al respecto, la vacuna heptavalente no cubre estos serotipos [60].

\section{Epílogo}

La vacunología puede reivindicarse como un ámbito de la medicina moderna que ha permitido un incremento espectacular de las expectativas de vida en los dos últimos siglos. No obstante, tal como se ha demostrado en esta breve revisión, existe todavía un cierto número de problemas pendientes de resolución antes de que sean eliminadas las infecciones actuales o, por lo menos, sometidas a control.

Gracias al notable trabajo del EPI, en 1990 se creyó que la tasa de vacunación global era del 80\%; sin embargo, desde entonces se ha estabilizado (o incluso ha descendido en algunos países), con un pequeño incremento durante los últimos años. Esto significa que del 15 al 25\% de los niños no están todavía inmunizados en todo el mundo. La comunidad internacional debe seguir dedicando los recursos necesarios, imprescindibles para acceder a estos desafortunados niños. Tal vez sea más importante reforzar los programas EPI nacionales o, incluso mejor, los sistemas sanitarios nacionales, con el objeto de obtener una mayor cobertura, que introducir vacunas nuevas, relativamente costosas, con una relevancia en ocasiones dudosa.

El programa de inmunización actual (6, 10 y 14 semanas) fue elaborado a comienzos de la década de los 80 para las vacunas DTT y VPO. Con un mejor conocimiento de las respuestas inmunitarias y la importancia de la inmunidad del grueso poblacional, pueden aparecer programas mucho mejores, por lo menos para algunos antígenos (Hib y neumocócico). Si tales programas permitieran la administración de dosis menores, se lograría una enorme ventaja, tanto práctica como económica. La pauta de vacunación nórdica (3 y 5 meses en una serie primaria más un refuerzo al cabo de 12 meses) podría tal vez aplicarse también en países en vías de desarrollo.

\section{Agradecimientos}

Los colegas que a continuación se citan han aportado comentarios valiosos sobre el manuscrito: Rashmi Rodriguez, Cecilia Young, Rose-Marie Carlsson, Bo Stensson y Hans K:son Blomquist.

\section{Bibliografía}

1 Medical milestones: poll results. BMJ, Jan 6, 2007. www.bmj.com/cgi/content/full/334/ suppl_1/DC3.

$\checkmark 2$ Burgess M: Immunisation: a public health success. NSW Public Health Bull 2003;14:1-5.

3 Henderson DA, Borio LL, Lane JM: Smallpox and vaccinia; in Plotkin SA, Orenstein WA (eds): Vaccines. Philadelphia, Saunders, 1999, pp 123-154.

4 WHO: Report of the Ad Hoc Committee on Orthopoxvirus Infections. Executive Board report $\mathrm{EB} / 95 / 33$, Oct 10, 1994.

5 World Health Assembly, item 12:2, Aug 18, 2007. www.who.int/gb/ebwha/pdf_files/ WHA60/A60_R1-en.pdf.

6 Casey CG, Iskander JK, Roper MH, et al: Adverse events associated with smallpox vaccination in the United States, January-October 2003. JAMA 2005;294:2734-2743.

$\checkmark 7$ Sejvar JJ, Labutta RJ, Chapman LE, et al: Neurologic adverse events associated with smallpox vaccination in the United States, 2002-2004. JAMA 2005;294:2744-2750.

8 Institute of Medicine/Committee on Smallpox Vaccination Program Implementation: The Smallpox Vaccination Programme: public health in an age of terrorism. March 3, 2005. www.nap.edu/catalog.php?record_ id $=11240 \#$ toc.
9 Global tuberculosis control - surveillance, planning, financing. WHO report 2007. WHO/HTM/TB/2007.376. www.who.int/tb/ publications/global_report/2007/introduction/en/index.html.

10 BCG vaccine. WHO position paper. Wkly Epidemiol Rec 2004;79:27-38.

11 Weill-Halle B: Oral vaccination; in Rosenthal SR (ed): BCG Vaccination against Tuberculosis. Boston, Little, Brown, 1957, pp 175-182.

12 Safety of BCG vaccine to HIV infected children. Global Advisory Committee on Vaccine Safety. Wkly Epidemiol Rec 2007;82: 18-24.

13 Diphtheria vaccine. WHO position paper. Wkly Epidemiol Rec 2006;81:24-32.

14 Wharton M, Vitek CR: Diphtheria toxoid; in Plotkin SA, Orenstein WA (eds): Vaccines. Philadelphia, Saunders, 1999, pp 211-228.

15 Mattos-Guaraldi AL, Moreira LO, Damasco PV, Hirata Junior R: Diphtheria remains a threat to health in the developing world - an overview. Mem Inst Oswaldo Cruz 2003;98: 987-993.

16 Long AP: Immunization to tetanus. Workshop on professional medical experiences in Japan and Korea 1950-53. Walter Reed Army Medical Center, April 29, 1954
17 Wassilak SGF, Roper MH, Murphy TV, Orenstein WA: Tetanus toxoid; in Plotkin SA, Orenstein WA (eds): Vaccines. Philadelphia, Saunders, 1999, pp 745-781.

18 Maternal and neonatal tetanus (MNT) elimination: the initiative and challenges. www. who.int/immunization_monitoring/diseases/MNTE_initiative/en/index.html.

19 Plotkin S: Aims, scope and findings of the global pertussis initiative. Pediatr Infect Dis J 2005;24:S5-S6.

20 Pertussis vaccines. WHO position paper. Wkly Epidemiol Rec 2005;80:31-39.

21 Singh M, Lingappan K: Whooping cough. The current scene. Chest 2006;130:15471553.

22 Tan T, Plotkin S: Controlling pertussis: considerations for the future. Pediatr Infect Dis J 2005;24:S98.

23 Tan T, Trindade E, Skowronski D: Epidemiology of pertussis. Pediatr Infect Dis J 2005; 24:S10-S18.

24 Robertson S: Module 6: Poliomyelitis. The Immunological Basis for Immunization Series. WHO/EPI/GEN/93.16. Geneva, WHO, 1993.

25 Axelsson P: The history of polio in Sweden - from infantile paralysis to polio vaccine. Sven Med Tidskr 2004;8:57-65.

26 www.polioeradication.org. 
27 Melnick JL: Poliomyelitis; in Warren K (ed): Tropical and Geographical Medicine, ed 2. New York, McGraw-Hill, 1990, pp 558-576.

28 Zamula E: A new challenge for former polio patients. FDA Consumer 1991;25:21-25.

29 Cohen MJ, Kaufman SR, Reiner BD: Aping science - a critical analysis of research at the Yerkes Regional Primate Research Center. Persp Med Res 1995;5:21-22. www.curedisease.com/Faqspolio.html.

30 Francis T, Korns R, Voight R, et al: An Evaluation of the 1954 Poliomyelitis Vaccine Trials. Ann Arbor, University of Michigan, 1955.

-31 Offit PA: The Cutter incident, 50 years later. N Engl J Med 2005;352:1411-1412.

- 32 Wesslén T, Lycke E, Gard S, Olin G: Inactivation of poliomyelitis virus by formaldehyde. Arch Gesamte Virusforsch 1957;7:125-135.

33 Pan American Health Organization: Proceedings of the 2nd International Conference on Live Poliovirus Vaccines. Washington, PAHO, 1960.

34 International notes certification of poliomyelitis eradication - the Americas 1994. Morb Mortal Wkly Rep 1994;43:720-722.

-35 General news. Major milestones reached in global eradication: Western Pacific region is certified polio-free. Health Educ Res 2001; 16:109.

36 European region of the World Health Organization. Europe achieves historic milestone as region is declared polio-free. Press release, June 21, 2002.

- 37 Progress towards poliomyelitis eradication in Nigeria, January 2005 to December 2006. Wkly Epidemiol Rec 2007;82:105-116.
38 Conclusions and recommendations of the Advisory Committee on Poliomyelitis Eradication, Geneva, 11-12 October, 2006. Wkly Epidemiol Rec 2006;81:453-464.

39 Pallansch MA, Sandhu HA: The eradication of polio - progress and challenges. $\mathrm{N}$ Engl J Med 2006;355:2508-2511.

40 Conclusions and recommendations of the Advisory Committee on Poliomyelitis Eradication, Geneva, 11-12 October, 2006. Wkly Epidemiol Rec 2006;81:465-468.

41 Meissner HC, Strebel PM, Orenstein WA Measles vaccines and the potential for worldwide eradication of measles. Pediatrics 2004; 114:1065-1069.

42 Drutz JE: Measles: its history and its eventual eradication. Semin Pediatr Infect Dis 2001:12:315-322.

43 Strebel PM, Papania MJ, Halsey NA: Measles vaccine; in Plotkin SA, Orenstein WA (eds): Vaccines. Philadelphia, Saunders, 1999, pp 389-440.

44 Cutts FT, Steinglass R: Should measles be eradicated? BMJ 1998;316:765-767.

45 Measles vaccine: WHO position paper. Wkly Epidemiol Rec 2004;79:130-142.

46 Expanded Programme on Immunization. Safety of high-titre measles vaccines. Wkly Epidemiol Rec 1992;67:357-361.

47 Measles: mortality reduction and regional elimination. Strategic plan 2001-2005. $\mathrm{WHO} / \mathrm{V} \& \mathrm{~B} / 01.13$.

48 Wolfson LJ, Strebel PM, Gacic-Dobo M, et al: Has the 2005 measles mortality reduction goal been achieved? A natural history modelling study. Lancet 2007;369:191-200.

-49 Davey S: Measles eradication still a long way off. Bull World Health Organ 2001;79:584585.
50 NHS Immunisation Statistics England 2006-2007. www.ic.nhs.uk/statistics-anddata-collections/health-and-lifestyles/immunisation.

51 Ashmore J, Addiman S, Cordery R, Maguire $\mathrm{H}$ : Measles in North East and North Central London, England: a situation report. Euro Surveill 2007;12E070920.2. www.eurosurveillance.org/ew/2007/070920.asp\#2.

52 van Treeck U: Measles outbreak in Germany: over 1,000 cases now reported in Nordrhein Westfalen. www.eurosurveillance.org/ew/ 2006/060511.asp.

53 Shann F: A little bit of measles does you good. BMJ 1999;319:4-5.

54 www.who.int/csr/disease/yellowfev/global partnership/en/index.html.

55 www.path.org/vaccineresources/hepb-indepth.php.

56 Chang M, Chen TH, Hsu HM, et al: Prevention of hepatocellular carcinoma by universal vaccination against hepatitis $B$ virus: the effect and problems. Clin Cancer Res 2005; 11:7953-7957.

57 WHO position paper on Haemophilus influenzae type b conjugate vaccines. Wkly Epidemiol Rec 2006;47:445-452.

58 Akumu AO, English M, Scott AG, Griffiths UK: Economic evaluation of delivering Haemophilus influenzae type $\mathrm{b}$ vaccine in routine immunization services in Kenya. Bull World Health Organ 2007;85:511-518.

59 Pneumococcal conjugate vaccine for childhood immunization - WHO position paper. Wkly Epidemiol Rec 2007;82:93-104.

60 Singh NK: Pneumococcal vaccine concerns: shape-shifters and beyond. Vaccine 2007;25: 5244-5245. 